\title{
Measurement of electrical potentials of the human rectum and pelvic colon in normal and aldosterone-treated patients
}

\author{
C. J. EDMONDS AND R. C. GODFREY \\ From the Medical Research Council Department of Clinical Research, University College Hospital \\ Medical School, London
}

SUMMARY A method is described which allows rapid measurement of the electrical potentia 5 difference across colonic mucosal epithelium to be carried out during routine sigmoidoscopy.․ㅡ․ The potential differences measured had a mean value of $25 \mathrm{mV}$ (range 4 to $51 \mathrm{mV}$ ) in $27 \vec{\omega}$ subjects with normal bowel. Six hours after two intravenous injections of $0.5 \mathrm{mg}$ aldosterones the potential difference had risen to $60 \mathrm{mV}$ (range 37 to $101 \mathrm{mV}$ ). The time course of responsesi studied after a single injection of aldosterone showed that the potential allowance rose withins four hours and had fallen again after 18 hours. Urinary sodium concentrations and sodium/ potassium ratios fell after aldosterone injections, the time course of the changes being similaro to that of the potential differences of the colon. Sodium concentration of stool fluid also fell. The concentration of chloride in the stool fluid was consistent with a passive distribution of 3 chloride according to the electrochemical gradient, but that of potassium was considerably? greater than expected from a passive distribution, suggesting that potassium is actively secreted? into the lumen of the colon.

An electrical potential difference is found across many epithelia even when no ionic gradients are present between the solutions bathing either side of the tissue. In general, these potential differences appear to result from the active transport of ions across the epithelia. Animal studies have shown that the colonic mucosa is polarized. the luminal side being negative with respect to the serosal side (Cooperstein and Brockman, 1959; Curran and Schwartz, 1960). The potential difference appears to be largely generated by the mucosal cells in the course of active transport of sodium across the mucosa from the lumen to the blood and rises considerably when sodium transport is stimulated by depleting animals of sodium or injecting aldosterone (Edmonds, 1967a; Edmonds and Marriott, 1967). Thus the colonic transmucosal potential difference reflects the most important function of the epithelial cells and its measurement could prove of value in assessing the functional state of the epithelium. The object of the present study was to develop a simple and rapid method for measuring the potential difference and apply it to the investigation of aldosterone action on human colon.

\section{Theoretical Basis of the Present Method}

In animal experiments it is possible to measure the true value of the transmucosal potential difference by placing monitoring electrodes on either side of $=$. the epithelium; even the peritoneum and smooth ${ }_{\sigma}$ muscle layer can be removed so that an electrode can be placed in close proximity to the serosal siden of the epithelial cells (Edmonds, 1967a). In $_{\sigma}^{\omega}$ investigations in man an electrode can easily be applied to the luminal surface of the mucosac (referred to subsequently as the 'probe' electrode),,$\stackrel{\Phi}{+}$ but it is not practicable to apply the other electrode (referred to as the 'reference' electrode) $\overline{0}$ directly to the serosal side of the epithelium. $A \vec{\otimes}$

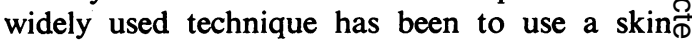
contact as reference electrode, one of the patient's $\frac{\varrho}{\sigma}$ fingers being placed in a saline solution. The skirt of the fingers is, however, polarized (Andersseno and Grossman, 1965) and in a previous study we? found that prolonged soaking was necessary too abolish this (Beck and Edmonds, unpublished? observations). An intravenous or subcutaneous electrode gives results similar to those obtained when the reference electrode is placed directly on 


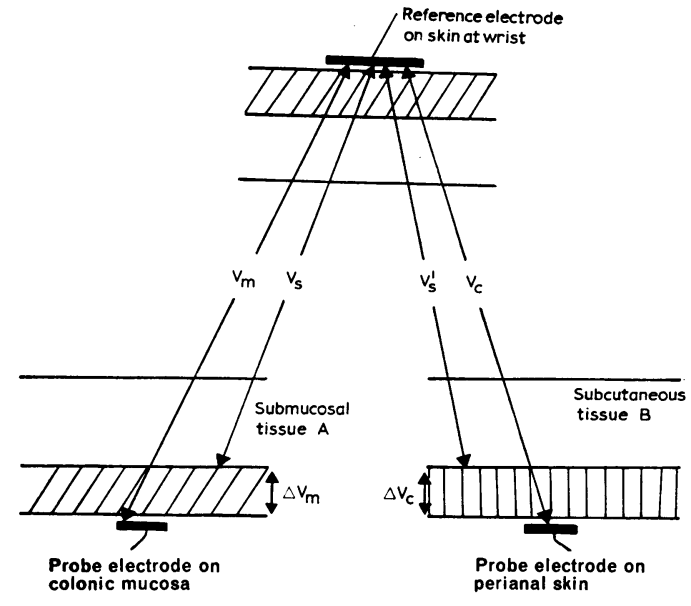

the serosal side of the epithelium (Edmonds, 1967a; Geall, McIrath, Phillips, Code, and Summerskill, 1968); the use of such reference electrodes does, however, appreciably complicate and prolong the procedure. For the majority of observations in the present study, the reference electrode was a metal plate placed on the forearm, good contact being ensured by use of an electrode jelly. The potential difference observed between this electrode and the probe electrode depended not only upon the potential difference present across the mucosal epithelium, but also on the potential difference present across the skin of the forearm and on any other sources of potential difference present between the skin and colonic mucosa. This difficulty was overcome by comparing the potential difference measured between the reference electrode and the probe placed on the mucosa $\left(V_{m}\right)$ with that observed when the probe was placed on perianal skin, 2 to $3 \mathrm{~cm}$ from the anus $\left(\mathrm{V}_{\mathrm{c}}\right)$. The principle is illustrated diagrammatically in Figure 1. It will be seen that:

and

$$
\begin{aligned}
& \Delta \mathbf{V}_{\mathrm{m}}=\mathrm{V}_{\mathrm{m}}-\mathrm{V}_{\mathrm{s}} \ldots \ldots \ldots \ldots \ldots \\
& \triangle \mathrm{V}_{\mathrm{c}}=\mathrm{V}_{\mathrm{c}}-\mathrm{V}_{\mathbf{s}^{\prime}} \ldots \ldots \ldots \ldots
\end{aligned}
$$

where $\Delta V_{m}$ and $\Delta V_{c}$ are the true transepithelial potential differences across mucosa and skin and $V_{s}$ and $V_{s}{ }^{\prime}$ represent the potential differences between the reference electrode and the subcutaneous tissues of the colonic mucosa and perianal skin. $V_{s}$ and $V_{s}^{\prime}$ may clearly include several potential differences produced in various tissues between the reference electrode and the subepithelial tissues of the colon and perianal skin, and will also include the asymmetry potential difference of the electrodes. The difference $\left(V_{A B}\right)$ between $V_{s}$ and $V_{s}{ }^{\prime}$ was equal to the potential difference between points $A$ and $B$. It would be expected that $V_{A B}$ would be very small since points $A$ and $B$ were close together, connected by extracellular fluid of relatively high conductivity, and with no obvious source of electromotive force between them. Although it has not been possible to demonstrate directly in man that $V_{G B}$ is negligible compared with $\Delta V_{m}$ it is possible to

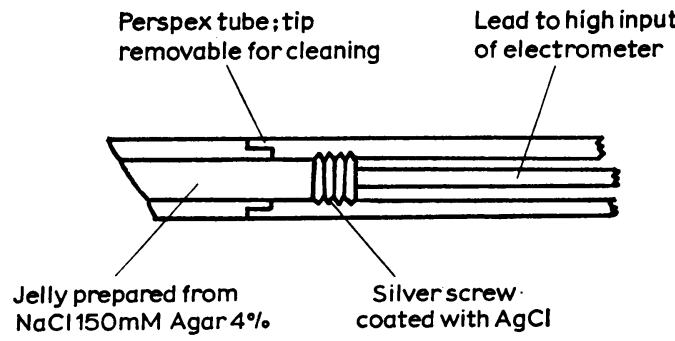

Fig. 1 Diagram to show the various potential differences present between the probe electrode and the reference electrode placed on the skin at the wrists.

Fig. 2 The probe electrode.

show in animal experiments that this is so (Edmonds, unpublished observations). We therefore assume that $V_{A B}=0$ and hence $V_{s}=V_{s}$. Then subtracting equation (1) from (2) gives,

$$
\Delta \mathrm{V}_{\mathrm{m}}=\mathrm{V}_{\mathrm{m}}-\mathrm{V}_{\mathrm{c}}+\Delta \mathrm{V}_{\mathrm{c}}
$$

Thus, providing the potential difference across the perianal skin, $\Delta V_{c}$, is small, the colonic transmucosal potential difference can be measured rapidly and simply by electrodes placed on the surface of the skin and the mucosa.

\section{Methods}

All the measurements were made while patients were in hospital or attending the outpatient department. They were carried out during the course of routine sigmoidoscopy, the measurements of the potential differences adding only a few minutes to the procedure. No patients who were found to have bowel disease were included in the present study. The experimental nature of the procedure was explained to all patients.

\section{APPARATUS FOR ELECTRICAL MEASUREMENTS}

The potential differences were measured using a high input impedance electrometer. ${ }^{1}$ The high input side of the instrument was connected to the probe electrode and the low input side to the reference electrodes.

The probe electrode (Fig. 2) was made from Perspex and contained a silver screw which had been previously coated with silver chloride. The cavity was filled with a jelly prepared from $4 \%$ agar- $150 \mathrm{mM}$ sodium chloride, and the tip could be unscrewed so that the electrode could be easily cleaned and filled with fresh jelly. The tip was angulated at about $45^{\circ}$, as preliminary trials showed that this gave better contact with the mucosa when the electrode was passed through the sigmoidoscope. After filling with jelly, the electrode was allowed to stand for at least 24 'Vibron model 33B, EIL. 


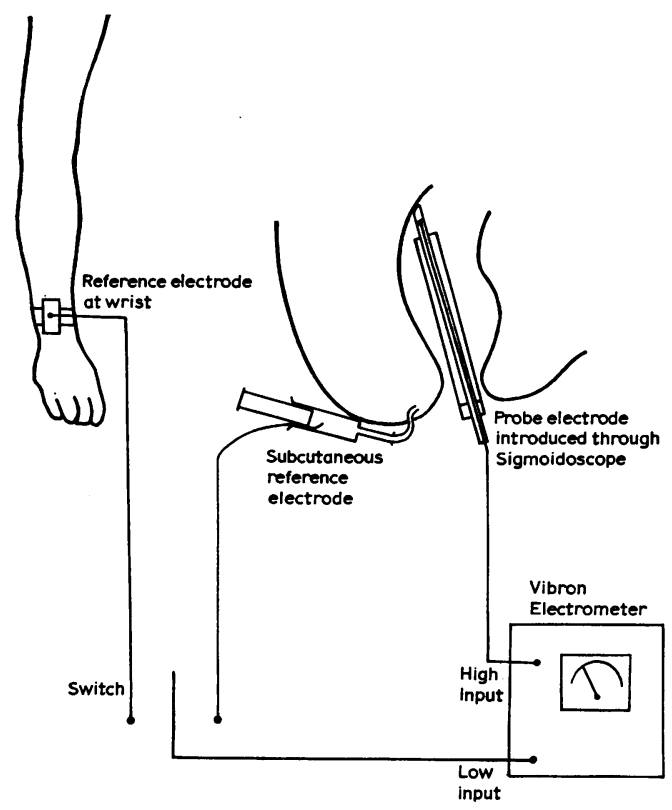

Fig. 3 Diagram to show positioning and connexion of electrodes. The skin reference electrode was used in the standard procedure, the subcutaneous reference being used on a few occasions only for comparison.

hours with its tip immersed in $\mathrm{NaCl} 150 \mathrm{mM}$. Subsequently the electrode was always stored with its tip in $\mathrm{NaCl} 150 \mathrm{mM}$ (containing $1 / 5000$ chlorhexidine) as it was important to avoid any drying of the agar jelly. If this happened air bubbles could be introduced, causing unstable and unreliable potential measurements.

The reference electrodes were of two types. In the majority of the investigations, two metal plates (as used in ECG recording) were strapped, one to each wrist. Good electrical contact was ensured by the use of Cambridge electrode jelly, and the plates were both connected to the low input side of the electrometer.

In some investigations where the potential difference across the skin was measured, a subcutaneous reference electrode was used. This was prepared by coating a fine silver wire with $\mathrm{AgCl}$ and subsequently allowing it to stand for 24 hours in $\mathrm{NaCl} 150 \mathrm{mM}$. Then by connecting it short-circuited for several hours with the probe electrode, the tips of both being placed in the same bath of $150 \mathrm{mM} \mathrm{NaCl}$, the electrodes were brought into balance, that is, the asymmetry potential difference between them was reduced to $1 \mathrm{mV}$ or less. The $\mathrm{Ag}-\mathrm{AgCl}$ wire was inserted immediately before use into a $10 \mathrm{ml}$ syringe filled with sterile $\mathrm{NaCl} 150 \mathrm{mM}$. This was connected to a sterile polythene cannula (diammeter $1 \mathrm{~mm}$ ) and passed through a hollow needle into the subcutaneous tissue 2 to $3 \mathrm{~cm}$ from the anal margin. About $0.5 \mathrm{ml}$ sterile saline was injected to ensure good electrical contact with the subcutaneous tissue. The arrangement of the three electrodes is shown in Figure 3.

\section{PROCEDURE OF MEASUREMENT}

The skin electrodes were placed on the wrists and, with the patient in the left lateral position, the $\Omega$ sigmoidoscope was inserted and sigmoidoscopy was carried out. To measure the potential $\overrightarrow{\vec{F}}$ difference the probe electrode was first moistened $\stackrel{0}{?}$ in $\mathrm{NaCl} 150 \mathrm{mM}$ and placed on the perianal skin $\frac{\mathrm{C}}{\circ}$ at about $2-3 \mathrm{~cm}$ from the anus. The potential $\frac{\bar{c}}{\bar{c}}$ difference $\left(V_{c}\right)$ between the skin reference $\vec{\Phi}$ electrodes and probe electrode on the perianal $\propto$ skin was then measured. This potential difference कै (referred to as the skin potential difference) was $\overrightarrow{0}$ usually about $200-300 \mathrm{mV}$ and was largely due to $\vec{\longrightarrow}$ the considerable asymmetry of the electrode $\omega_{\sigma}$ measuring system. Using the 'backing off' device $\widehat{O}$ of the electrometer, the potential difference could $\risingdotseq$ be opposed, so that the meter reading was reduced $\overrightarrow{-}$ to any chosen level. Our procedure was to apply enough 'backing off' electromotive force so that all readings could be made on the $100 \mathrm{mV}$ scale. The probe electrode was then moistened again with $\mathrm{NaCl} 150 \mathrm{mM}$, passed through the sigmoido- $\rightarrow$ scope, and applied to the mucosa under direct vision. A steady potential difference could be $\overrightarrow{\vec{\varphi}}$ read within a few seconds and was recorded, and $\varphi$ is subsequently referred to as the 'mucosal. potential difference' $\left(V_{m}\right)$. The probe electrode was removed, moistened again with $\mathrm{NaCl} 150 \mathrm{mM}$, and replaced on the skin and the skin potential difference checked. The procedure was repeated to obtain three satisfactory sets of measurements at each point, every mucosal reading being preceded and followed by a measurement of the skin potential difference. Although usually the skin potential difference altered relatively little between the readings (not by more than $5 \mathrm{mV}$ ), sometimes a comparatively large drift occurred. When this happened the observations were rejected and the measurements repeated. It was important to inspect the electrode periodically to ensure that it was undamaged and that no air bubbles were present. After use the probe electrode was thoroughly cleaned before sterilization by standing it for 30 minutes in $150 \mathrm{mM}$ $\mathrm{NaCl}$ containing $1 / 5000$ chlorhexidine.

\section{ALDOSTERONE ADMINISTRATION}

One or two doses, each of $500 \mu \mathrm{g}$, aldosterone (Ciba) were given intravenously in about $2 \mathrm{ml}$ of physiological saline. Where a single dose was $\stackrel{?}{?}$ given, it was injected either two, four, or six 7 hours before the measurements were made. Where two doses were given, one was injected two hours after the other and the measurements were made six hours after the first dose.

MEASUREMENTS ON URINE AND STOOLS

A sample of urine was obtained after the sigmoidoscopy from the aldosterone-treated subjects and from some of the untreated normal subjects. The first stool sample passed after 
Measurement of electrical potentials of the human rectum and pelvic colon

sigmoidoscopy was collected whenever possible. The stool fluid was obtained by a method developed by one of us (C.J.E.) which involved ultracentrifugation at $30,000 \mathrm{rpm}^{1}$ followed by rapid filtration under reduced pressure through a Gellman membrane filter, pore size $1 \cdot 2 \mu^{2}$. Sodium and potassium estimations were carried out by flame photometry and chloride was estimated by potentiometric titration.

\section{Results}

MEASUREMENT OF POTENTIAL DIFFERENCE USING A SUBCUTANEOUS ELECTRODE

As indicated in the theoretical treatment, measurement of the 'true' potential difference $\left(\Delta V_{m}\right)$ across the intestinal mucosa by the present method was influenced by the potential difference across the perianal skin $\left(\Delta V_{c}\right)$. To estimate $\Delta V_{c}$, an additional reference electrode consisting of a $\mathrm{Ag}-\mathrm{AgCl}$ wire mounted in a syringe was employed when measurements were made in some subjects. It was connected by polythene tubing filled with saline to the subcutaneous tissue at about $3 \mathrm{~cm}$ from the anal margin. The polythene tubing was introduced through a hollow needle but the latter was removed once the tubing was in position. Good electrical contact was indicated by the stability of the recordings. Then, connecting the subcutaneous electrode to the low input lead of the electrometer, potential difference measurements were made with the probe electrode placed first on the perianal skin and then on the mucosa. Thus in these patients $\Delta V_{c}$ and $\Delta V_{m}$ were measured directly. The balance of the electrodes themselves was determined before and after each study with the tip of the polythene tube and of the probe electrode placed in a beaker of $150 \mathrm{mM}$ sodium chloride. Appropriate correction for potential difference asymmetry was made where necessary but generally the electrodes differed by less than $2 \mathrm{mV}$. In the five patients studied the mean value of the skin potential difference was $11 \mathrm{mV}$ (range 7 to $16 \mathrm{mV}$ ) and in all instances the subcutaneous electrode was positive with respect to the probe electrode. In two of the patients, intravenous injections of aldosterone, $0.5 \mathrm{mg}$, were given at four hours and six hours before the measurements but there was no evidence that aldosterone significantly affected the potential difference across the skin. When the potential difference across the mucosa was measured using the subcutaneous reference electrode it was always higher than that obtained using our standard procedure with metal electrodes placed on the arms. The difference between the values obtained by the two methods in each subject was in good agreement with the value of the trans-skin potential difference, $\Delta V_{c}$, as

\begin{tabular}{|c|c|c|c|}
\hline & $\begin{array}{l}V_{m} \\
(m V)\end{array}$ & $\begin{array}{c}V_{c} \\
(m V)\end{array}$ & $\begin{array}{l}\text { Mean Value } \\
\left(V_{m}-V_{c}\right)\end{array}$ \\
\hline \multirow{2}{*}{\multicolumn{4}{|c|}{$\begin{array}{l}\text { Potential difference measurements with reference electrode on wris } \\
\text { Perianal skin }\end{array}$}} \\
\hline & & & \\
\hline $\begin{array}{l}\text { Mucosa }(8 \mathrm{~cm}) \\
\text { Perianal skin }\end{array}$ & & 270 & \\
\hline Mucosa $(8 \mathrm{~cm})$ & 212 & & -55 \\
\hline Perianal skin & & 268 & \\
\hline Mucosa (8 cm) & 216 & & \\
\hline Perianal skin & & 270 & \\
\hline \multicolumn{4}{|c|}{$\begin{array}{l}\text { Potential difference measurements with reference electrode } \\
\text { connected to subcutaneous tissue }\end{array}$} \\
\hline Perianal skin & & 14 & \\
\hline Mucosa $(8 \mathrm{~cm})$ & 74 & & \\
\hline Perianal skin & & 16 & \\
\hline Mucosa $(8 \mathrm{~cm})$ & 76 & & \\
\hline Perianal skin & & 15 & \\
\hline Mucosa $(8 \mathrm{~cm})$ & 73 & & \\
\hline
\end{tabular}

Table I An example of potential difference measurements ${ }^{1}$ in one patient treated with aldosterone

'When potential difference measurements were made with the reference electrode on the wrist the probe electrode was connected to the high input of the electrometer, with the high input positive. The negative sign attached to $\left(V_{m}-V_{c}\right)$ indicates therefore that the lumen was negative with respect to the submucosa. Where the reference electrode was connected to the subcutaneous tissue the probe electrode was connected to the high input, with the high input as negative.

expected from the theoretical considerations. The typical protocol shown in Table I illustrates this point.

\section{NORMAL MUCOSAL POTENTIAL DIFFERENCE}

Figure 4 shows the combined results for measurements in 27 normal subjects taken at various levels from $4 \mathrm{~cm}$ to $14 \mathrm{~cm}$ from the anal margin. It will be seen that there is considerable variation in potential difference from one individual to another, but that the mean values at each level did not differ significantly. There was very little change of potential difference as the probe electrode was moved from one site to another in this part of the colon. In some initial experiments the potential difference was recorded at levels more distant than $14 \mathrm{~cm}$ from the anus but these did not significantly differ from the more easily accessible regions and so in the majority of investigations measurements were only made below 14 centimetres.

The mean value of all the results in Fig. 4 is $25 \mathrm{mV}$, but the true transmucosal potential difference $\left(\triangle V_{m}\right)$ would be greater by about $10 \mathrm{mV}$, as the value of $\Delta V_{c}$ must be added to the recorded values of $V_{m}-V_{c}$ to obtain the true potential difference (equation 3).

EFFECT OF ALDOSTERONE ON POTENTIAL DIFFERENCE Figure 5 shows the effect of aldosterone given by intravenous injection in two doses each of $0.5 \mathrm{mg}$ at four hours and six hours before the measurements were made. It is clear that the potential difference values were considerably greater than in 


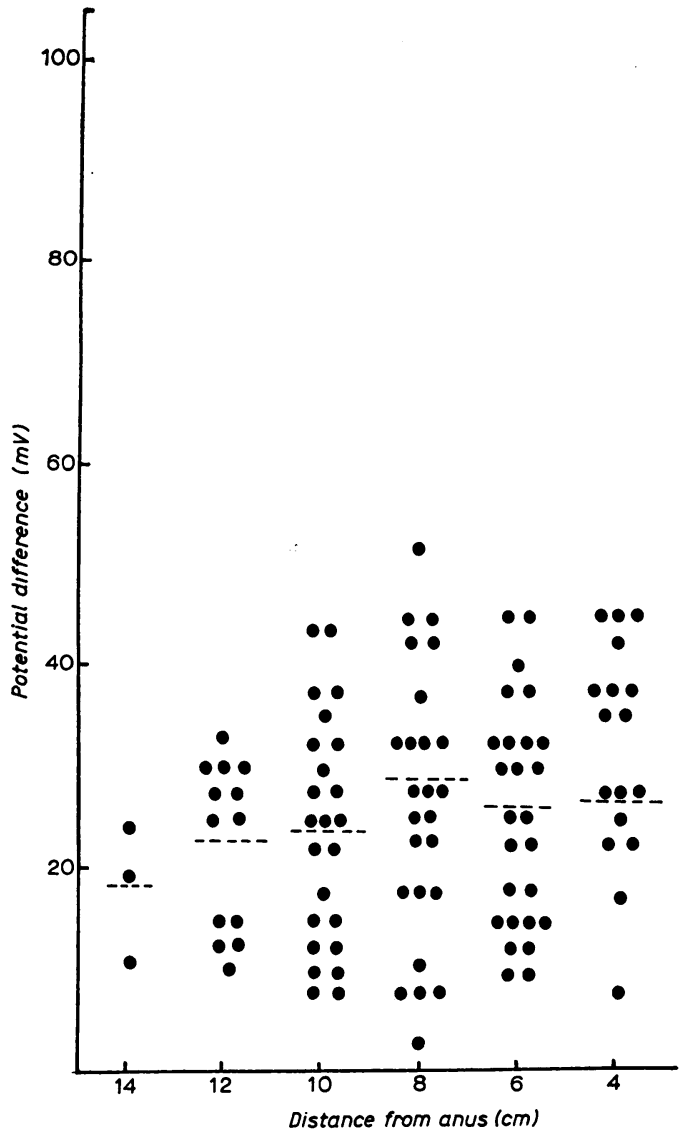

Fig. 4 Combined results of measurements in 27 normal patients. The potential differences recorded represent the value $V_{m}-V_{c}$ and approximately $10 \mathrm{mV}$ should be added to obtain the true transmucosal potential difference, $\triangle V_{m}$.

untreated patients. The elevation of potential difference occurred at all levels of the colon studied in the present investigation. Here also in order to obtain the true transmucosal potential difference $\left(\triangle V_{m}\right) 10 \mathrm{mV}$ must be added to the recorded potential difference $\left(V_{m}-V_{c}\right)$ to allow for the trans-skin potential difference $\left(\triangle V_{c}\right)$. The mean value of all the readings on Fig. 5 is $60 \mathrm{mV}$, and the increase in potential difference compared with normal subjects not treated with aldosterone is highly significant at all levels.

\section{TIME COURSE OF ALDOSTERONE EFFECT}

When two injections of aldosterone were given, the potential difference was considerably elevated by six hours after the first dose. In an attempt to define the time relationships more clearly, a single dose of $0.5 \mu \mathrm{g}$ of aldosterone was given intravenously to seven patients and measurements of colonic potential differences carried out at various times subsequently. At two hours after aldosterone administration, there was no definite evidence that the potential difference was greater

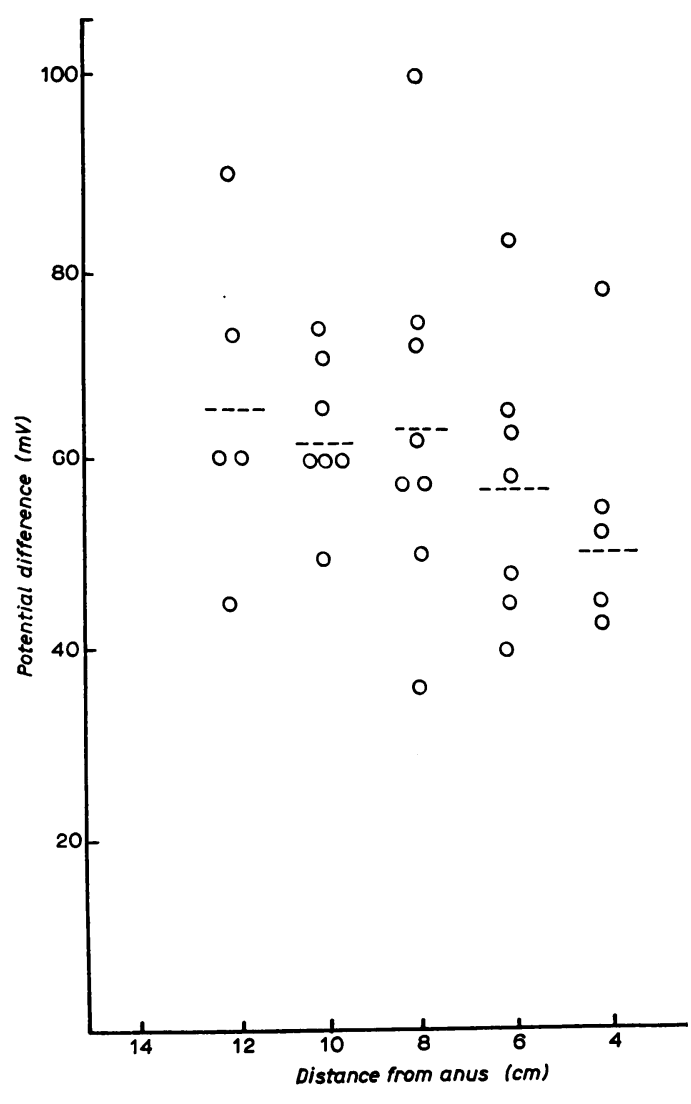

Fig. 5 Combined results from eight patients after administration of aldosterone. Approximately $10 \mathrm{mV}$ should be added to obtain the true transmucosal potential difference, $\triangle V_{m}$.

than normal, the mean value being $30 \pm 2 \cdot 8 \mathrm{mV}$ (SE based on nine measurements in three patients). By four hours after aldosterone, the potential difference was significantly raised $(P<0.005)$, 은 being $40 \pm 3.4 \mathrm{mV}$ (SE based on eight measure- $\rightarrow$ ments in three patients) and by six hours it was $37 \pm 2 \cdot 2$ (SE based on eight measurements on two N patients). In one patient, measurements were repeated on the following day, 18 hours after aldosterone administration, and the potential dif- $\omega$ ferences were then found to be within normal limits again. Thus it appears that aldosterone

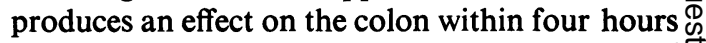
after it has been given and that the action is of ${ }^{+}$ relatively short duration having disappeared by 18 hours. Changes in the urinary sodium $/ \mathbb{\Phi}$ potassium ratio clearly had a similar time $\frac{\mathcal{P}}{\mathbb{D}}$ course (Figure 6). The single dose of aldosterone $\varrho$ produced a potential difference change considerably less than that observed with the two doses. This is in general agreement with the results? of animal studies showing that the magnitude of potential difference change is linearly related to $\risingdotseq$ the logarithm of the amount of aldosterone administered when this approximates to physiological levels (Edmonds and Marriott, 1969). 


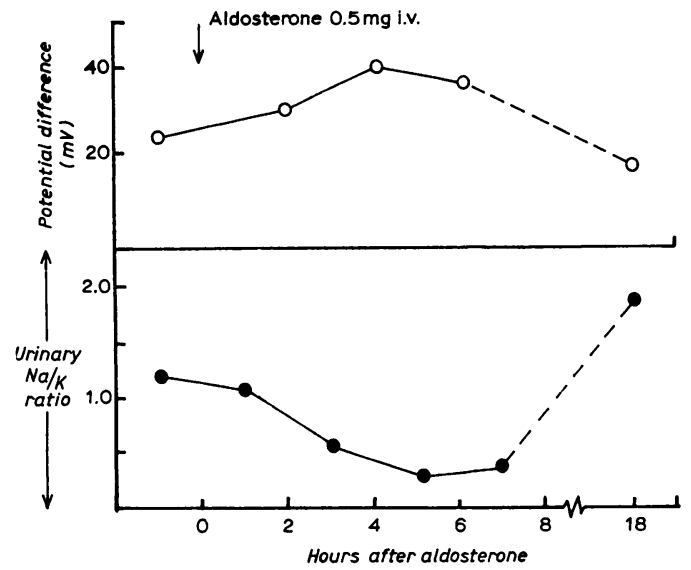

Fig. 6 Time course of potential difference response of rectal mucosa compared with that of sodium/potassium ratio in urine in patients given a single intravenous injection of $0.5 \mathrm{mg}$ aldosterone. The potential difference values are means based on observations made in seven patients while urinary sodium/potassium ratios are moans derived from data obtained from three patients.

\section{ELECTROLYTE CONTENT OF STOOLS AND URINE}

Urine samples were collected after sigmoidoscopy from many of the normal subjects and from all of those who received aldosterone. The first stools passed after sigmoidoscopy were also collected and the stool water was extracted.

The dose of aldosterone used produced marked change in urine composition (Table II) with a significant fall in the urinary sodium/potassium ratio. The stool fluid also showed changes, the sodium concentration being reduced and the potassium concentration being increased by aldosterone treatment, although probably the latter change was not significant.

COMPARISON OF THE STOOL FLUID ELECTROLYTE VALUES WITH THOSE EXPECTED FROM THE ELECTROCHEMICAL GRADIENT ACROSS MUCOSA

The predominant cation in the stool water was potassium both in the normal subjects and in patients treated with aldosterone, and the present values are quite close to those obtained when an in-vivo dialysis technique was used to sample stool water (Wrong, Metcalfe-Gibson, Morrison, $\mathrm{Ng}$, and Howard, 1965). The question arises as to whether the observed potassium concentration could be accounted for by the potential difference since this was orientated so as to favour the accumulation of cations in the lumen.

If the potassium concentration of the faecal water was simply a result of the plasma and the electrical potential difference, the colonic mucosa behaving inertly with respect to the ion, then the equilibrium value could be calculated from the Nernst equation:

$$
[\mathrm{K}]_{\mathbf{l}}=[\mathrm{K}]_{\mathrm{p}} \exp \left(\Delta \mathrm{V}_{\mathrm{m}} \mathrm{F} / \mathrm{RT}\right)
$$

where $[K]_{1}$ is the luminal and $[K]_{p}$ the plasma $K$ concentration and $\Delta V_{m}$ is the electrical potential difference across the colonic mucosa. T, F, and $\mathbf{R}$ are the absolute temperature, the Faraday, and the gas constant respectively. The ionic strengths of the faecal solution and of the plasma were similar so that activity coefficients could be omitted. Clearly from Table III, the observed potassium concentrations were considerably less than expected from simple passive distribution of the ion.

\begin{tabular}{llllll}
\hline \multirow{2}{*}{ Subject } & \multicolumn{2}{c}{ Potassium } & (m-equiv/l) & & \multicolumn{2}{c}{ Chlorine (m-equiv/l) } \\
\cline { 2 - 3 } \cline { 5 - 6 } & Calculated & Observed & & Calculated & Observed \\
\hline $\begin{array}{l}\text { Normal } \\
\begin{array}{l}\text { Aldosterone- } \\
\text { treated }\end{array}\end{array}$ & 16 & 87 & 28 & 18 \\
\hline
\end{tabular}

Table III Comparison of potassium and chloride concentrations observed in stool fluid with those calculated from the Nernst equation

${ }^{1}$ The calculated values were obtained using the Nernst equation as described in the text. Mean values of plasma potassium and chloride concentrations were taken $(4 \cdot 4$ and $105 \mathrm{~m}$-equiv/l respectively) and in normal subjects the mean transmucosal potential difference was taken as $35 \mathrm{mV}$ and in aldosterone treated as $70 \mathrm{mV}$.

In the case of chloride, the concentrations observed here were similar to those found with the in-vivo dialysis technique (Wrong et al, 1965).

\begin{tabular}{|c|c|c|c|c|c|c|c|c|}
\hline \multirow[t]{2}{*}{ Subject } & \multirow{2}{*}{$\begin{array}{l}\text { Number } \\
\text { of } \\
\text { Cases }\end{array}$} & \multicolumn{4}{|l|}{ Stool Fluid } & \multicolumn{3}{|l|}{ Urine } \\
\hline & & $\begin{array}{l}\text { Sodium } \\
(m \text {-equiv } / l)\end{array}$ & $\begin{array}{l}\text { Potassium } \\
(m-e q u i v / l)\end{array}$ & $\begin{array}{l}\text { Chlorine } \\
\text { (m-equiv } / l)\end{array}$ & $\begin{array}{l}\text { Sodium/ } \\
\text { Potassium }\end{array}$ & $\begin{array}{l}\text { Sodium } \\
(m-e q u i v / l)\end{array}$ & $\begin{array}{l}\text { Potassium } \\
(m-e q u i v / l)\end{array}$ & $\begin{array}{l}\text { Sodium/ } \\
\text { Potassium }\end{array}$ \\
\hline \multirow{2}{*}{$\begin{array}{l}\text { Normal } \\
\text { Patients treated with } \\
\text { aldosterone }\end{array}$} & 10 & $30 \pm 3 \cdot 5$ & $87 \pm 10.8$ & $18 \pm 2 \cdot 2$ & $0.36 \pm 0.09$ & $119 \pm 25$ & $52 \pm 8 \cdot 7$ & $2 \cdot 4 \pm 0.66$ \\
\hline & 8 & $19 \pm 1 \cdot 4$ & $112 \pm 5 \cdot 1$ & $15 \pm 2 \cdot 5$ & $0.15 \pm 0.02$ & $32 \pm 3.6$ & $64 \pm 8 \cdot 4$ & $0.53 \pm 0.11$ \\
\hline Significance & & $<0.002$ & 0.04 & $\mathrm{NS}^{2}$ & 0.025 & $<0.002$ & NS & $<0.01$ \\
\hline
\end{tabular}

Table II Electrolyte composition of urine and stool fluid ${ }^{1}$

${ }^{1}$ Urine was collected after sigmoidoscopy and the stool fluid was obtained from the first stool specimen passed.

${ }^{2}$ Not significant 
For chloride the Nernst equation can also be applied (Table III). The calculated and observed concentrations did not appear to differ from each other more than expected in view of the considerable variation in chloride concentration of stool fluid. Thus, for chloride, the present results, like those obtained by animal experiments (Curran and Schwartz, 1960), were consistent with the hypothesis that chloride ions move passively across the colonic mucosa according to the chemical and electrical potential gradients.

\section{Discussion}

A potential difference across an epithelium can be produced in several ways. If the solutions bathing the two sides of the epithelium differ in composition or concentration, then a diffusion potential may be present comparable to that which may be found in non-living systems. If the membrane restricts the diffusion of some of the ions present, such potentials can be of considerable magnitude (for example, see Sollner, 1958). Plainly therefore it is important that when the potential difference is measured in the gut, the solution bathing the luminal side of the mucosa should be clearly defined. In the present experiments, the composition of the electrode and of the solution used to moisten the mucosa, namely, $\mathrm{NaCl} 150 \mathrm{mM}$, differed little, as regards the principal ions present, from that of extracellular fluid bathing the other side of the epithelium, so that diffusion potentials probably contributed little to the potential differences observed.

There is now substantial evidence that colonic mucosa actively transports sodium from the lumen to the extracellular fluid (Cooperstein and Hogben, 1959; Curran and Schwartz, 1960). Further it has been shown in rats that the colonic potential difference is principally related to the luminal sodium concentration and can be reduced or abolished by agents, eg, ouabain, known to impair active sodium transport in many tissues (Edmonds and Marriott, 1968a, b). That sodium is absorbed by human colon is clear from the difference in volume and composition between ileal and faecal fluid. Sodium absorption has also been demonstrated by perfusion experiments (Duthie and Atwell, 1963; Shields and Miles, 1965; Devroede and Phillips, 1969). Although these findings in man do not prove conclusively that sodium absorption by the human colon does represent active sodium movement, nevertheless by analogy with animal experiments it seems likely that this is so. Probably therefore the potential differences we observed across human colonic mucosa when no significant ionic gradients were present resulted from active transport of sodium ions from the lumen to the extracellular fluid, thereby polarizing the tissue.

The present experiments showed that in man aldosterone produces a considerable rise in the transmucosal potential difference with a time course similar to that observed in rats (Edmonds 9 and Marriott, 1967). Levitan and Ingelfinger? (1965), measuring absorption rates of sodium, $\overrightarrow{\overline{\vec{N}}}$ chloride, and water in perfused human colon ino unanaesthetized patients, observed an increase of about $50 \%$ in sodium and fluid absorption rates after $1 \mathrm{mg}$ of aldosterone had been given, but the effect was delayed for 24 hours. Crocker ando Munday (1969), using an in-vitro preparation of ${ }^{\text {s }}$ rat jejunum, also observed a considerable delay in aldosterone action, there being no increase of sodium absorption rate until 27 hours aftero administration. So great a delay in the onset of action of aldosterone is unlike that found in other tissues (Ross, 1959; Sharp and Leaf, 1966) $\overrightarrow{\dot{ }_{\vec{A}}}$ or in animal experiments on the colon, or in thew present study on human colon. As neither of the above groups recorded electrical changes, the explanation of the difference between theirobservations and ours regarding the time of onset of aldosterone action must at presene. remain unresolved.

The sodium concentration in the stool fluid wass significantly reduced by aldosterone treatment although not to the extent observed in clinicap hyperaldosteronism (Milne, Muehrcke, and Aird 1957; Richards, 1969) or when repeated aldosterone injections were given (Charron, Leme? Wilson, Ing, and Wrong, 1969). At first this seems surprising since the changes of potentia $\vec{P}$ differences indicated a considerable increase of sodium absorption. The most probable explan ation lies in the relatively short time for which the mucosa was subjected to stimulation by aldo sterone as the patients received only two intra venous injections. The relatively small changes produced in stool fluid composition probably was consistent with the action of aldosterone as indicated by the potential differences changes which had a delay of onset of only two to threes hours yet were transient, being no longer eviden? 18 hours later.

Increased potassium concentration in the stoo? water is a feature of hyperaldosteronism (Richards 1969), and a marked increase in the rate of potassium secretion by colonic mucosa is als produced by aldosterone both in man and animaks (Shields, Mulholland, and Elsmlie, 1966 ह Edmonds and Marriott, 1967; Shields, Miles; and Gilbertson, 1968). The lack in the presento study of any significant effest on the potassiunit concentration of faecal fluid again probably? reflects the relatively short period of exposure to aldosterone. In both the normal patients and those treated with aldosterone a considerable discrepancy existed between the potassiurie concentration found in the stool fluid and that to be expected if the distribution of the ion across the epithelium were simply passive (Table III). The discrepancy might be accounted for in several ways. One possibility was that the potential 
difference was considerably greater at more proximal regions of the bowel not accessible to measurement in the present study. The evidence of animal experiments is against such an explanation as the potential difference tends to be lower in the proximal regions of the large intestine, although plainly without direct measurement it is impossible to be certain that this is also true in man. Another possibility was that the high potassium concentration resulted from the considerable water absorption that occurs in the colon. Providing potassium permeability were low, a high potassium concentration might then result, the Nernst equation not being applicable as the system was deviating considerably from equilibrium. Against this explanation is the substantial body of evidence showing that colonic mucosa is not poorly permeable to potassium; passive potassium permeability is probably at least as great as the passive sodium permeability (Shields, 1966; Edmonds, 1967b). The most likely explanation therefore seemed to be that in man, as in the rat (Edmonds, 1967b) and possibly in the dog (Phillips and Code, 1966), colonic mucosa possesses a mechanism which transfers potassium from the plasma to the lumen against the electrochemical gradient.

In conclusion, the present results show that by using a skin reference electrode and a simple probe electrode placed alternately on perianal skin and mucosal epithelium, it is possible to estimate the potential difference of the mucosa of rectum and colon and easily demonstrate the electrical change produced by aldosterone. The method is very simple, adding a few minutes only to sigmoidoscopy, and so can be easily used in routine work. The fact that exogenous aldosterone produces marked changes of potential difference in so easily accessible a region suggests the use of the method in screening for aldosteronism. Further, since sodium transport is a major function of the epithelial cells of large intestine, measurement of potential difference may well prove useful in objective assessments of the functional state of the mucosa, as for example, in disease states such as ulcerative colitis.

\section{References}

Anderssen, S., and Grossman, M. I. (1965). Profile of $p H$, pressure and potential difference at gastroduodenal junction in man. Gastroenterology, 49, 364-371.

Charron, R. C., Leme, C. E., Wilson, D. R., Ing, T. S., and Wrong, O. M. (1969). The effect of adrenal steroids on stool composition, as revealed by in vivo dialysis of faeces. Clin. Sci., 37, 151-167.

Cooperstein, I. L.. and Brockman, S. K. (1959). The electrical potential difference generated by the large intestine: its relation to electrolyte and water transfer. J. clin. Invest., $38,435-442$.

Cooperstein, I. L., and Hogben, C. A. M. (1959). Ionic transfer across the isolated frog large intestine. J. gen. Physiol., $42,461-473$.

Crocker, A. D., and Munday, K. A. (1969). Factors affecting mucosal water and sodium transfer in everted sacs of rat jejunum. J. Physiol. (Lond.), 202, 329-338.
Curran, P. F., and Schwartz, G. F. (1960). Na, Cl, and water transport by rat colon. J. gen. Physiol., 43, 555-571.

Devroede, G. J., and Phillips. S. F. (1969). Conservation of sodium, chloride, and water by the human colon. Gastroenterology, 56, 101-109.

Duthie, H. L., and Atwell, J. D. (1963). The absorption of water, sodium, and potassium in the large intestine with particular reference to the effects of villous papillomas. Gut, 4, 373-377.

Edmonds, C. J. (1967a). The gradient of electrical potential difference and of sodium and potassium of the gut contents along the caecum and colon of normal and sodiumdepleted rats. J. Physiol. (Lond.), 193, 571-588.

Edmonds, C. J. (1967b). Transport of potassium by the colon of normal and sodium-depleted rats. J. Physiol.(Lond.), 193, 603-617.

Edmonds, C. J., and Marriott, J. C. (1967). The effect of aldosterone and adrenalectomy on the electrical potential difference of rat colon and on the transport of sodium, potassium, chloride and bicarbonate. J. Endocr., 39, 517-531.

Edmonds, C. J., and Marriott, J. C. (1968a). Electrical potential and short circuit current of an in vitro preparation of rat colon mucosa. J. Physiol. (Lond.), 194, 479-494.

Edmonds, C. J., and Marriott, J. C. (1968b). Factors influencing the electrical potential across the mucosa of rat colon. J. Physiol. (Lond.), 194, 457-478.

Edmonds, C. J., and Marriott, J. C. (1969). The effect of aldosterone on the electrical activity of rat colon.J. Endocr., 44, 363-377.

Geall, M. G., McIrath, D. C., Phillips, S. F., Code, C. F., and Summerskill, W. H. J. (1968). Measurement of the transmucosal potential difference of stomach in unanesthetized man. (abstr.) Gastroenterology, 54, 1235.

Levitan, R., and Ingelfinger, F. J. (1965). Effect of d-aldosterone on salt and water absorption from the intact human colon. J. clin. Invest., 44, 801-808.

Milne, M. D., Muehrcke, R. C., and Aird, I. (1957). Primary aldosteronism. Quart.J. Med., 26, 317-333.

Phillips, S. F., and Code, C. F. (1966). Sorption of potassium in the small and the large intestine. Amer. J. Physiol., 211, 607-613.

Richards, P. (1969). Clinical investigations of the effects of adrenal corticosteroid excess on the colon. Lancet, 1, 437-442.

Ross, E. J. (1959). Aldosterone in Clinical and Experimental Medicine, p. 50. Blackwell, Oxford.

Sharp, G. W., and Leaf, A. (1966). Mechanism of action of aldosterone. Physiol. Rev., 46, 593-633.

Shields, R. (1966). Absorption and secretion of electrolytes and water by the human colon, with particular reference to benign adenoma and papilloma. Brit. J. Surg., 53, 893-897.

Shields, R., and Miles, J. B. (1965). Absorption and secretion in the large intestine. Postgrad med. $J, 41,435-439$.

Shields, R., Miles, J. B., and Gilbertson, C. (1968). Absorption and secretion of water and electrolytes by the intact colon in a patient with primary aldosteronism. Brit. med. J., 1, 93-96.

Shields, R., Mulholland, A. T., and Elmslie, R. G. (1966). Action of aldosterone upon the intestinal transport of potassium, sodium, and water. Gut, 7, 686-696.

Sollner, K. (1958). The physical chemistry of ion exchange membranes. Svensk. kem. T., 6-7, 267-295.

Wrong, O. M., Metcalfe-Gibson, A., Morrison, R. B. I., Ng, S. T., and Howard, A. V. (1965). In vivo dialysis of faeces as a method of stool analysis. Clin. Sci., 28, 357-375. 